\title{
Quality of Integrated Management of Newborn and Childhood Illness Services at Health Centers in Jimma, Southwest Ethiopia
}

This article was published in the following Dove Press journal: Patient Preference and Adherence

\author{
Musa Kumbi Ketero \\ Abduljewad Hussen \\ Muhammed iD \\ Adem Abdulkadir Abdi (iD \\ Department of Public Health, Goba \\ Referral Hospital, Madda Walabu \\ University, Goba, Ethiopia
}

Background: The Integrated Management of Newborn and Childhood Illness (IMNCI) strategy includes both preventive and curative interventions to improve practices in health facilities, the health system and at home. The quality of these interventions has been very rarely subjected to scientific inquiry in Ethiopia. This study assessed quality of IMNCI services in health centers of Jimma, South West Ethiopia, 2014.

Methods: A facility based cross-sectional study was conducted from March 2-15, 2014 in the health centers of Jimma among 411 care takers exit interview and total of 60 consultation sessions were observed using checklist and participants enrolled through convenient sampling technique. Descriptive statistics were used and factor analysis was employed to create measurement scales for satisfaction of caretakers. Factor scores were used in linear regression analyses to determine presence of statistically significant association between explanatory variables and the outcome variable at $\mathrm{P}$ value $<0.05$.

Results: The response rate for the exit interview was $411(97.4 \%)$. The mean score of overall caretakers satisfaction was 63.4 . Specifically $23.4 \%, 33.6 \%$, and $19.2 \%$ of the respondents were dissatisfied with waiting time, amount of explanation they received about the problem or treatment, and availability of medicines, respectively. Availability of prescribed medications (95\% CI: 0.577 to 0.047$)$, receiving first dose of medication at health facility (95\% CI: $0.087,0.552)$, receiving laboratory services $(95 \% \mathrm{CI}: 0.455,0.056)$ were among factors that significantly associated with the caretakers' satisfaction score.

Conclusion and Recommendations: Perceived mean of caretakers' satisfaction at the health centers of Jimma town was low as compared to national standards and long waiting time while providing services. Availability of prescribed medications, receiving first dose of medication and receiving laboratory services were factors associated with patients' satisfaction. Respective health centers need to ensure availability of medications and supplies and professionals need to pay special attention on medical services like laboratory services, medication and decrease waiting time while providing health services.

Keywords: Integrated Management of Newborn and Childhood Illnesses, quality, satisfaction, Jimma

\section{Background}

The Integrated Management of Newborn and Childhood Illnesses (IMNCI) approach is a broad strategy, encompassing interventions at home and in the healthcare facilities to reduce childhood deaths, illnesses and disabilities and to contribute to improved growth and development. IMNCI is a child survival strategy developed by the World Health Organization (WHO) and United Nations Children's Fund (UNICEF). ${ }^{1,2}$
Correspondence: Adem Abdulkadir Abdi Tel +251920323417

Email ademabdi8@gmail.com
Patient Preference and Adherence 2021:15 793-805 
Nearly 7 million children die every year in the world, before reaching their fifth birthday and most of these deaths occur during their first year of life. Majority of the deaths take place in developing countries. ${ }^{10}$ More than $50 \%$ of these deaths are attributed to diarrhea, acute respiratory infections (ARI), malaria or measles. ${ }^{8,11}$ Every day millions of parents take children with potentially fatal illnesses to firstlevel health facilities with signs and symptoms related to more than one condition. This overlap means that a single diagnosis may not be possible or appropriate and that treatment may be complicated by the need to combine therapy for several conditions and so it is important to treat the child as a whole and not simply his or her most obvious disease. Hence, the initial focus of IMNCI has been on improving their performance through training and support. ${ }^{4,8,12}$

Multiple bottlenecks such as imperfect supervision and monitoring mechanism; inadequate availability of basic equipments and drug supplies; inefficient referral system; poor training in terms of quality and duration; lack of regular reinforcement of guidelines; and poor performance of health care staff have been recognized which were arresting the reach of IMNCI in the community. ${ }^{5,6,17-19}$ Efforts to improve the quality of child health services provided by PHC workers in the less developed countries should focus not only on resource-intensive structural improvements, but also on cheap, cost-effective measures that address actual delivery of services (process), especially the proper use of national guidelines for case management, and meaningful supervision. ${ }^{20}$

In Ethiopia, according to 2011 Ethiopian demographic and health survey (EDHS), one in every 17 children dies before their first birthday, and one in every 11 dies before their fifth birthday. ${ }^{21}$ The most frequent illness was cough or cold (44.8\%), followed by diarrhea (32.8\%), fever $(22.4 \%)$, and anemia $(6 \%) .^{5}$

It is estimated that some $50-70 \%$ of Quality of IMNCI standards are being regularly implemented by hospitals and health centers, with the standards relating to outpatient services, inpatient services, and pharmacy services most effectively implemented. Implementation of referral and nursing standards are also partially being implemented. ${ }^{23}$ Based on this, Quality of IMNCI services is unknown in the study area. Thus, this study was conducted to assess IMNCI services quality at the health centers of Jimma.

\section{Methods}

\section{Study Area, Design and Period}

The study data was collected from March 25-April 15, 2014 in the health centers of Jimma. Jimma is among one of towns found in Oromia regional state and is located at $357 \mathrm{~km}$ from Addis Ababa. The town has 17-kebeles ${ }^{4}$-rural and 13-urban kebeles with total population of 174,778 of which 28,664 and 5418 are under five and under one year age respectively. There are two governmental hospitals including Jimma university specialized teaching hospitals, three fully functional health centers and one health center on construction and two health posts. Also there are four ${ }^{4}$ NGO clinics, 22 private medium clinics, five higher clinics, 47 drug stores and pharmacies, and other health facilities (unpublished data; Annual report of Jimma Town health office; Office Jimma Town Health; 2013). A facility-based cross sectional study design was used in the study.

\section{Source and Study Populations}

All children aged under five, and their caretakers in Jimma, were included in the source Population. Moreover, all health professionals and heads of health centers involved in the delivery and management of IMNCI services in the health centers were part of the source population. The study population included a sample of mothers/caretakers of children aged under five who came to the sick baby clinic in the health centers of Jimma during the study period. In addition, a purposive sample of health professionals and heads of the health centers involved in the delivery and management of IMNCI services in the health centers were included in the study. Patients with severe disease were excluded in the study.

\section{Sample Size Determination}

The sample size was determined by single population proportion formula using the following assumptions (Level of significance of the population was taken to be $95 \%, \mathrm{Z} \alpha / 2=1.96)$. A $5 \%$ level of precision $(\mathrm{d}=$ 0.05 ) and $50 \%$ proportion of caretakers satisfied with IMNCI service $(\mathrm{P}=0.5)$ and the yields of sample size calculation were 384. By considering a non-response rate of $10 \%$, the final sample size was 422 . Two IMNCI service providers and heads of health centers were interviewed for each health centers and 
60 consultation sessions were observed in the three health centers.

\section{Sampling Technique and Sampling Procedures}

All three functional health centers found in the Jimma town were included. Desired sample size at each of the centers was determined by a proportional to size allocation based on numbers of client visits of most recent quarter report of each health centers. Convenient sampling technique was employed to select study participants.Finally, consecutive clients were included in the study until the allocated sample size was obtained in each of the three health centers.

Two service providers (those who have more experience and providing services in each health centers) were selected purposively and heads of health centers was interviewed about the availability of necessary resources for IMNCI service provision by using interviewer administered semistructured questionnaire. Sick children were randomly selected for observation based on the number of clients expected for each day of the survey. Where many sick child were present and eligible for observation, the rule is to observe a maximum of five clients for each health centers per day, with a minimum of 20 observations in all three health centers. In order to achieve the target number of observations, systemic sampling technique was used, thus observation session was selected by dividing the total number of expected clients with expected observation in one facility to derive the "3rd" interval for selecting the next client to be observed. ${ }^{45}$

\section{Measurement Data Collection Instruments and Procedures}

A questionnaire prepared by DHS for child health service quality assessment was adopted to the local condition (health centers) and it was developed to conduct structured interview for service provider, face-to-face exit interview for mothers/caretakers and a standard checklist for inventory and Observation. ${ }^{46}$ IMNCI guidelines provide the standard against which service provision was assessed. ${ }^{47}$

The first is an inventory of resources. Head of the health centers were interviewed for inventory information and it was verified by observation. These was to gather information on the availability of specific items (including their location and functional status), and facility infrastructure, including the service delivery environment. The resources assessed were those required to provide service at nationally accepted standard. The second is service provider interview. Two health service providers were interviewed from each health center for information on their qualifications (training, experience, and continued education), supervision they have received, and perceptions of the service delivery environment by using interviewer administered structured questionnaire.

The third is an observation protocol tailored to the service being provided. Direct observations were conducted during consultations to assess the extent to which service providers comply to the service delivery standards based on national accepted components for good service delivery. The process used when conducting specific procedures, physical examinations, and the content of information exchanged between the provider and client (history, symptoms, and advice) were components of the observation.

The fourth is face-to-face exit interview with the clients who received service during the data collection using structured questionnaire. The exit interview assessed the client's understanding of the consultation/examination, as well as recall of instructions received for treatment or preventive behaviors and on their perceived satisfaction on the services they received (after provider classification and treatment). Clients were interviewed after they completed the service in comfortable and isolated place.

Variables in the study were mothers'/caretakers' satisfaction as dependent variable and independent variables were Service availability, Availability of equipment and supplies, Opening time, Counseling of clients, Referral system, Availability of guideline, Staffing training, Supervision, Quality assurance, Waiting area, Waiting time, Information provision and Socio-demographic and socio-economic characteristics of caretakers (age, sex, family income, educational level, occupation status, religion, marital status).

\section{Data Processing and Analysis Procedures}

To ensure high-quality of information the data were checked for completeness. Data were entered into EPIDATA version 3.1, and then exported to SPSS version 16.0 for analysis. Descriptive statistics like frequencies, mean, proportion, graphs and charts were used to present study results. One-way ANOVA (analysis of variance) was used for comparing perceived caretakers satisfaction score among health facilities. Perceived mean of satisfaction of caretakers was measured using a Likert scale having 11 items. Reliability check showed that the scale had high internal consistency (Cronbach's $\alpha=0.884$ ). 
The Kaiser-Meyer-Olkin (KMO) measure, correlation of variable, homoscedasticity and normality of distributions was checked. The KMO measure of sampling adequacy and Bartlett's test of sphericity was carried out. The $\mathrm{KMO}$ value was 0.827 which means the data were appropriate for factor analysis. The Bartlett's test of sphericity was significant $(\mathrm{p}<0.001)$. To examine the underlying factors of the scale, exploratory factor analysis was conducted and only one factor with eigenvalue greater than one was identified (named as perceived caretakers satisfaction score) and it explained $62.7 \%$ of the overall variance. Using this regression factor score created further analysis was performed. After bivariate analysis was done and variables with $\mathrm{p}$ value $<0.25$ were selected for entry in the final model. Then multiple linear regression analysis was performed and the association of explanatory variables on the regression factor score of the dependent variable was quantified and significance of the findings was considered at $p<0.05$. Enter method was employed to enter independent variables into both the first and the final model.

\section{Data Quality Management}

To ensure the completeness, accuracy and consistency of data collection, a session was held each day of the data collection period. During each session thorough checking was done before receiving the filled questionnaires from each data collector, which helps to crosscheck for their performance and improving proper data collection. The data were explored using descriptive analyses to clean data entry errors. The client exit interview questionnaire was translated into Afan Oromo and Amharic version by qualified individual graduate and back translated to English, to check for consistency by different persons. The inventory and service provider questionnaire was collected by principal investigator.

Three diploma nurses and one supervisor (BSc. nurse) graduate participated in data collection after they were informed of the aim and principle of the study. After their willingness to participate in the study they received two days' training from a principal investigator. Each data collector was exposed to training before the start of any actual work.

Pre-test was undertaken in Serbo health centers outside of the study area. The selected health center for pre-test assumed that it had all the required facilities for service and similar with selected health centers. In the presence of principal investigator both the interviewers and supervisor assessed clarity, understandability, flow of questions, the time needed to fill the questionnaires and completeness of the questions. Then, after through discussions some minor modification and omissions was made in some of the ambiguous questions. Data collection took place immediately after approval of the proposal by the university. Three trained nurses and a Bsc. nurse graduate supervisor with the assistance of principal investigator participated throughout the data collection.

\section{Operational Definitions}

Quality: is a multidimensional concept, but in this study, it was measured in terms of caretakers satisfaction, availability of necessary resource and compliance of service with national guideline for IMNCI service provision. $^{24}$

Resource availability: encompasses availability of necessary resource inputs for IMNCI provision such as features of the setting the number and types of personnel, the age and type of equipment and other facilities, and aspects of organization such as administration structures.

Level of compliance includes the content of information shared for the caretakers during consultation and observation based on IMNCI national guideline Caretakers' satisfaction: perceived opinion of care received from IMNCI services/staff by caretakers. Perceived mean of caretakers' satisfaction was measured using a Likert scale having 11 items. Each item was scored on a 5-point scale ranging from 1 - very dissatisfied to 5 - very satisfied which yields a score range of $11-55$.

Perceived mean of caretakers' satisfaction score was calculated based on percentage of possible maximum scale score $(\% \mathrm{SM}){ }^{48}$

$$
\% \mathrm{SM}=\frac{(\text { actual score }- \text { minimum possible score }) \times 100}{(\text { Maximum possible score }- \text { minimum possible score })}
$$

Waiting time was the time clients had to wait before receiving their services after arrived at Facility.

\section{Results}

The response rate for the exit interview was 411 (97.4\%), of which $80 \%$ and $77.1 \%$ of them were females and mothers, respectively. Nearly half of respondents were Muslim and Oromo $(52.8 \%$ and $51.8 \%$, respectively). The mean age of the respondents was 28.2 (SD of 6.4) years and ranging between 17 and 57 years. About $94(22.9 \%)$ of the respondents cannot 
Table I Socio-Demographic Characteristics of Caretakers and Sick Children at Health Centers of Jimma Town, 2014

\begin{tabular}{|c|c|c|c|}
\hline $\begin{array}{l}\text { Socio- } \\
\text { Demographic } \\
\text { Variables }\end{array}$ & Response Category & $\begin{array}{c}\text { Frequency } \\
(n=4 I I)\end{array}$ & $\%$ \\
\hline \multirow[t]{2}{*}{ Sex of caretaker } & Male & 82 & 20.0 \\
\hline & Female & 329 & 80.0 \\
\hline \multirow[t]{3}{*}{ Age of caretaker } & $15-24$ & 106 & 25.8 \\
\hline & $25-34$ & 320 & 56.0 \\
\hline & $\geq 35$ & 75 & 18.2 \\
\hline \multirow{2}{*}{$\begin{array}{l}\text { Relationship of } \\
\text { caretakers to the } \\
\text { child }\end{array}$} & Mothers & 317 & 77.1 \\
\hline & Others* & 74 & 22.9 \\
\hline \multirow[t]{7}{*}{ Ethnic group } & Oromo & 213 & 51.8 \\
\hline & Amhara & 89 & 21.7 \\
\hline & Keffa & 21 & 5.1 \\
\hline & Dawro & 27 & 6.6 \\
\hline & Gurage & 21 & 5.1 \\
\hline & Yemi & 25 & 6.1 \\
\hline & Others** & 15 & 3.6 \\
\hline \multirow[t]{4}{*}{ Marital status } & Married & 370 & 90.0 \\
\hline & Single & 15 & 3.6 \\
\hline & Divorced & 18 & 4.4 \\
\hline & Widowed & 8 & 2.0 \\
\hline \multirow[t]{4}{*}{ Religion } & Muslim & 217 & 52.8 \\
\hline & Orthodox & 127 & 30.9 \\
\hline & Protestant & 57 & 13.9 \\
\hline & Catholic & 10 & 2.4 \\
\hline \multirow{5}{*}{$\begin{array}{l}\text { Educational } \\
\text { status }\end{array}$} & Illiterate & 94 & 22.9 \\
\hline & Read and write only & 41 & 10.0 \\
\hline & Primary $(I-8)$ & 150 & 36.5 \\
\hline & Secondary $(9-12)$ & 80 & 19.4 \\
\hline & College and above & 46 & 11.2 \\
\hline
\end{tabular}

Table I (Continued).

\begin{tabular}{|c|c|c|c|}
\hline $\begin{array}{l}\text { Socio- } \\
\text { Demographic } \\
\text { Variables }\end{array}$ & Response Category & $\begin{array}{c}\text { Frequency } \\
(n=4 I I)\end{array}$ & $\%$ \\
\hline \multirow{7}{*}{$\begin{array}{l}\text { Occupational } \\
\text { status }\end{array}$} & Housewife & 197 & 47.9 \\
\hline & Farmer & 36 & 8.8 \\
\hline & Government employee & 38 & 9.2 \\
\hline & Private employee & 43 & 10.5 \\
\hline & Private business & 23 & 5.6 \\
\hline & Daily laborer & 13 & 3.2 \\
\hline & Merchant & 61 & 14.8 \\
\hline \multirow[t]{2}{*}{ Sex of the Child } & Male & 216 & 52.6 \\
\hline & Female & 195 & 47.4 \\
\hline \multirow{4}{*}{$\begin{array}{l}\text { Age of the child } \\
\text { (in months) }\end{array}$} & $<12$ & $|5|$ & 36.7 \\
\hline & $12-\leq 24$ & 140 & 34.1 \\
\hline & $24-\leq 36$ & 74 & 18.0 \\
\hline & $>36$ & 46 & 11.2 \\
\hline
\end{tabular}

Notes: Mean (SD) age in months=19.7 (SD of 1.5). Others* (siblings, grandmother/father), others** (Tigre, Siltie, Woleyta).

read and write and $46(11.2 \%)$ were college and above by educational status. The majority $(197 ; 47.9 \%)$ of the responds were housewives. Over three-quarters (317; $77.1 \%$ ) of the sick children were brought to the health centers by their mothers (Table 1).

\section{Structural Attributes of Quality}

Basic child health services like child curative service, growth monitoring, child immunization, TB/leprosy diagnosis, HIV counseling and testing (HCT) and laboratory service were provided in all of the three health centers. Services like diagnosis and treatment of malnutrition, vitamin A supplementation, iron and zinc supplementation were also part of child curative service in all of the health centers (Table 2).

Concerning training and support of health workers, out of interviewed health service providers two of them 
Table 2 Availability of Equipment for IMNCI Service at Sick Baby Clinic in Health Centers of Jimma Town, 2014

\begin{tabular}{|l|l|l|l|}
\hline Equipment & $\begin{array}{l}\text { Jimma } \\
\text { Health Center }\end{array}$ & $\begin{array}{l}\text { Higher Two } \\
\text { Health Center }\end{array}$ & $\begin{array}{l}\text { Kochi Mandera } \\
\text { Health Center }\end{array}$ \\
\hline $\begin{array}{l}\text { Child weighing scale (250gram gradation) } \\
\text { Infant weighing scale(100 gram gradation) }\end{array}$ & I* & I & I \\
Thermometer & I & 0 & 0 \\
Stethoscope & I & I & 0 \\
Timer or watch with seconds hand & I & I & I \\
Calibrated I/2 or I-liter measuring jar for ORS & $0 *$ & I & I \\
Cup and spoon & 0 & I & I \\
Examination bed & 0 & 0 & I \\
Height or length board & I & I \\
Tape for measuring circumference & I & I \\
\hline
\end{tabular}

Notes: I $^{*}$ - available and observed, $0^{*}$ - not available and observed.

were diploma holders in clinical nursing whereas four were health officers. None of service providers have received/took training within the past 24 months on the topic related to child health or childhood illness.

Table 3 Symptoms of Children Seeking Medical Advice at the Survey Time in Health Centers of Jimma Town, $2014(n=4 I I)$

\begin{tabular}{|c|c|c|c|}
\hline $\begin{array}{l}\text { Symptoms/ } \\
\text { Complaints }\end{array}$ & $\begin{array}{l}\text { Response } \\
\text { Category }\end{array}$ & Frequency & $\%$ \\
\hline \multirow[t]{2}{*}{ Fever } & Yes & 247 & 60.1 \\
\hline & No & 164 & 39.9 \\
\hline \multirow{2}{*}{$\begin{array}{l}\text { Cough or difficulty } \\
\text { breathing }\end{array}$} & Yes & 181 & 44.0 \\
\hline & No & 230 & 56.0 \\
\hline \multirow[t]{2}{*}{ Diarrhea } & Yes & 160 & 38.9 \\
\hline & No & 251 & 61.1 \\
\hline \multirow[t]{2}{*}{ Ear problem } & Yes & 46 & 9.7 \\
\hline & No & 365 & 90.3 \\
\hline \multirow[t]{2}{*}{ Skin problems } & Yes & 35 & 3.4 \\
\hline & No & 376 & 96.6 \\
\hline \multirow[t]{2}{*}{ Eye symptoms } & Yes & 19 & 4.6 \\
\hline & No & 392 & 95.4 \\
\hline \multicolumn{2}{|l|}{ Others* } & 16 & 3.9 \\
\hline \multirow[t]{4}{*}{ Duration of symptoms } & One day & 44 & 10.7 \\
\hline & Two days & 54 & 13.1 \\
\hline & Three days & 104 & 25.3 \\
\hline & $\begin{array}{c}\text { Four and more } \\
\text { days }\end{array}$ & 209 & 50.9 \\
\hline
\end{tabular}

Note: Others* (injury, throat problem, dog bite).
Almost all service providers provide all basic child health service in their current position and as part of their work for the facility. Almost all service providers reported that there was no written job description. Salary supplement mentor and nonmonetary incentives ever received by service providers include monthly salary supplement, perdiem when attending trainings, duty allowance, vacation/time off, training, and uniforms.

Table 4 Information on the Treatment and Caretaker Comfort Level at Health Centers of Jimma Town, 2014

\begin{tabular}{|c|c|c|c|}
\hline Variables & $\begin{array}{l}\text { Response } \\
\text { Category }\end{array}$ & Frequency & $\%$ \\
\hline \multirow[t]{2}{*}{ Medicines prescribed } & Yes & 376 & 91.5 \\
\hline & No & 35 & 8.5 \\
\hline \multirow{2}{*}{$\begin{array}{l}\text { Information on the } \\
\text { availability of } \\
\text { prescribed } \\
\text { medications }\end{array}$} & $\begin{array}{l}\text { Received all } \\
\text { medications }\end{array}$ & 265 & 70.5 \\
\hline & $\begin{array}{l}\text { Received Some } \\
\text { medication and } \\
\text { or prescription }\end{array}$ & 111 & 29.5 \\
\hline \multirow{2}{*}{$\begin{array}{l}\text { Explanation on how to } \\
\text { give the medications }\end{array}$} & Yes & 300 & 97.7 \\
\hline & No & 7 & 2.3 \\
\hline \multirow{2}{*}{$\begin{array}{l}\text { Caretakers correctly } \\
\text { knew all the dose and } \\
\text { frequency of each } \\
\text { medication }\end{array}$} & Yes & 296 & 96.4 \\
\hline & No & 11 & 3.6 \\
\hline \multirow{2}{*}{$\begin{array}{l}\text { A dose of any } \\
\text { medications given to } \\
\text { the child at the facility }\end{array}$} & Yes & 53 & 17.3 \\
\hline & No & 254 & 82.7 \\
\hline \multirow[t]{2}{*}{ Child weighed } & Yes & 157 & 38.2 \\
\hline & No & 254 & 61.8 \\
\hline
\end{tabular}




\section{Compliance to Consultation Standards} Exit Interview

The most common complaints of sick children were fever (60.1\%), cough/difficult breathing (44\%), diarrhea (38.9\%) and followed by ear problems (9.7\%). Only 44 $(10.7 \%)$ of the children sought medical advice within one day of complaint and about half(209; 50.9\%) of them within four and more days of the start of symptoms (Table 3).

Regarding Information provided to the care taker, more than half $(245 ; 59.6 \%)$ of caretakers were informed about the illness the child had. Nearly half $(199 ; 48.4 \%)$ of the caretakers were informed/notified on the signs and symptoms that would necessitate immediate return to health facility. Out of those symptoms, $166(83.4 \%)$ and 11 (5.5\%) respondents were informed if symptoms became worse and poor/not eating or drinking respectively.

Out of the 218 (53.0\%) respondents advised to bring the child back to the health centers for none emergency reasons, $30(15.5 \%), 31(16.1 \%)$, and 17 (8.8\%) of them were for more medicine, follow up, and immunization respectively. About $283(68.9 \%)$ and $128(31.1 \%)$ of the respondents intended to visit the same health facility and other health facility if the child was failed to improve or became worse respectively.

The majority of respondents (296; 96.4\%) felt comfortable or confident that they knew how much of each medication to give their child each day and for how many days to gave it. Only $53(17.3 \%)$ of the children received their first dose of medication at the facility before they left. About 157 (38.2\%) of the children were weighed at the time of their visit and $20(12.7 \%)$ caretakers were informed on the growth status of their children (Table 4).

The mean waiting time for the respondent was 44.6 minutes (SD of 3.5) before being seen. An out of pocket payment system was the only way of getting service and no prepayment plan was available. Accordingly, 393 (95.6\%) paid for the service they got. The majority of respondents $(371 ; 90.3 \%)$ visited the health center nearest to their home and $40(9.7 \%)$ did not visit a nearby health center. The main reason they did not visit the nearest health center was lack of medicine and good service provision, which accounts for $75 \%$ and $65 \%$, respectively.

The majority of the respondents $(352 ; 85.60 \%)$ recommended that their friends or family visit the facility. Among major suggestions for improvements made by respondents was to improve the supply of drugs and regularly availing the service providers on time that accounts for $179(43.6 \%)$ and $181(44 \%)$ respectively.

\section{Observation}

Observations on 60 clients were done to assess compliance to standards while they receive the service in sick baby clinic.

Table 5 Caretaker's Satisfaction on the IMNCI Service Provision at Health Centers of Jimma Town, 2014

\begin{tabular}{|c|c|c|c|c|c|}
\hline Statements & $\begin{array}{l}\text { Very Dissatisfied } \\
\text { (n/\%) }\end{array}$ & $\begin{array}{l}\text { Dissatisfied } \\
\text { (n/\%) }\end{array}$ & $\begin{array}{c}\text { Neutral } \\
(\mathbf{n} / \%)\end{array}$ & $\begin{array}{l}\text { Satisfied } \\
(\mathbf{n} / \%)\end{array}$ & $\begin{array}{l}\text { Very Satisfied } \\
(\mathrm{n} / \%)\end{array}$ \\
\hline Time you waited to see a provider & $58(14.0)$ & $96(23.4)$ & $9(2.2)$ & $166(40.4)$ & $82(20)$ \\
\hline Ability to discuss problems or concerns about illness & $27(6.6)$ & $132(32.1)$ & $44(10.7)$ & $160(38.9)$ & $48(I 1.7)$ \\
\hline $\begin{array}{l}\text { Amount of explanation you received about the } \\
\text { problem or treatment }\end{array}$ & $28(6.8)$ & $138(33.6)$ & $42(10.2)$ & $152(37.0)$ & $5 I(12.4)$ \\
\hline Privacy from having others see the examination & $9(2.2)$ & $52(12.6)$ & $87(21.2)$ & $228(55.5)$ & $35(8.5)$ \\
\hline $\begin{array}{l}\text { Privacy from having others hear your consultation } \\
\text { discussion }\end{array}$ & $\mathrm{II}(2.7)$ & $50(12.2)$ & $88(21.4)$ & $220(53.5)$ & $42(10.2)$ \\
\hline Availability of medicines at this facility & $37(9.0)$ & $19(19.2)$ & $21(5.1)$ & $149(35.3)$ & $129(31.4)$ \\
\hline The hours of service at this facility & $10(2.4)$ & $73(17.8)$ & $76(18.5)$ & $198(48.2)$ & $54(13.1)$ \\
\hline The number of days services are available to you & $9(2.2)$ & $64(15.6)$ & $63(15.3)$ & $226(55.0)$ & $49(11.9)$ \\
\hline The cleanliness of the facility & $15(3.6)$ & $80(19.5)$ & $32(7.8)$ & $208(50.6)$ & $76(18.5)$ \\
\hline How the staff treated you & $9(2.2)$ & $86(20.9)$ & $30(7.3)$ & $|7|(4 \mid .6)$ & $115(28.0)$ \\
\hline Price for services or treatments & $8(1.9)$ & $31(7.5)$ & $12(2.9)$ & $214(52.2)$ & $146(35.5)$ \\
\hline
\end{tabular}


The mean consultation duration was 11.9 (SD of 4.0) and ranged between 5-22 minutes. About $44(73.3 \%)$ of them asked whether the child had cough or difficulty breathing. Only $10(16.7 \%)$ respondents were asked about history of tuberculosis infection in any parents in the last 5 years and none of the respondents were asked about mothers HIV status.

During physical examination, for half $(30 ; 50 \%)$ of the sick children their temperature were checked using a thermometer and 21 (35\%) of them were weighed. None of the cases were checked for neck stiffness, pallor by looking at palms and conjunctiva, plotted weight on growth chart and enlarged lymph nodes in 2 or more of the following sites (neck, axillae, groin).

Concerning counseling of caretakers during observation, Only $11(18.3 \%)$ caretakers were informed about child feeding, even when the child was not sick. Nine $(15 \%)$ of them were advised to give extra fluid to the child during illness and $18(30 \%)$ of the providers advised the caretaker to continue feeding the child during illness. Six $(10 \%)$ of the clients were informed about what illness the child had. Only 8 (13.3\%) were notified of signs and symptoms for which they should immediately bring the child back to the health center. None of providers used a visual aid to educate the caretaker.

\section{Caretakers' Satisfaction}

The mean score of overall satisfaction (as the percentages of maximum scale scores) on IMNCI service provision was 63.4 (SD of 18.9). Regarding each item, more than half (55.5\%) and $(55.0 \%)$ of the caretakers were satisfied with privacy from having others see the examination and the number of days services are available to them, respectively. However, $23.4 \%$ and $33.6 \%$ of the respondents were dissatisfied with waiting times and the amount of explanation they received about the problem or treatment, respectively. The result of a one-way ANOVA shows that there is no significant difference on mean of caretakers' satisfaction scores among three health centers [F $(2406)=1.672$, P-value $=0.189]$ (Table 5)

\section{Factors Associated with Caretakers' Satisfaction}

Based on the outputs of simple linear regression analysis age, sex, educational status, telling the name of child illness, availability of prescribed medications, receiving first dose of medications, receiving laboratory services and recommending health facility for relatives or friends were the variables that candidates for the final model.

From multiple linear regression analyses the independent predictors of perceived caretakers' satisfaction in this study were the availability of prescribed medications, information provided to the caretakers on the child's illness, receiving the first dose of medications at the facility, receiving laboratory services and recommending health facility for relatives or friends.

Accordingly, caretakers who had received some medication had an average decrease of 0.312 units in perceived satisfaction score when compared to those who had received all medications (95\% CI: 0.047, 0.577). Respondents who were told about their child's illness had average increases of 0.223 in satisfaction score when compared to those who were not told (95\% CI: 0.041 to 0.406). Those respondents that received laboratory services had on average 0.256 units perceived higher satisfaction scores when compared to their counterparts $(95 \% \mathrm{CI}$ : $0.056,0.455)$. Those caretakers whose child received their first dose of medication at health facility had on average 0.320 units higher perceived satisfaction scores when compared to their counterparts (95\% CI: 0.087 to 0.552). Caretakers those recommending health facility for relatives or friends had on average 0.670 higher satisfaction scores when compared to their counterparts (95\% CI: 0.387 to 0.952 ) (Table 6 ).

\section{Discussion}

This study identified constraints in sick baby clinics in Jimma town health centers related to quality of IMNCI service provision. This study showed that the mean score of overall satisfaction of caretakers on IMNCI service provision was 63.4 (SD of 18.9) and the mean of waiting time for the respondents was 44.6 minutes (SD of 3.5). Availability of prescribed medications (95\% CI: 0.577 to $0.047)$, receiving first dose of medication at a health facility (95\% CI: 0.087 to 0.552 ), receiving laboratory services (95\% CI:0.455,0.056) were among factors that significantly associated with the caretakers' satisfaction score.

According to this study more than half (59.6\%) of the caretakers knew their child illness. This finding was higher than the study done in Jigawa, Nigeria, only $5.1 \%$ of mothers/caretakers knew about their child's illness. ${ }^{37}$ The difference might be due to the differences in geographical areas covered by these studies in which about three districts were included for the Jigawa study but our study confined to only one town.

This study revealed that majority of the caretakers $(70.8 \%)$ did not receive any information about feeding of solid foods and giving fluids (or breast milk) during the visits. This finding was in line with the study done in Nnewi of Nigeria. ${ }^{30}$ However, it was higher than the 
Table 6 Final Model Predicting Perceived Caretaker's Satisfaction with the IMNCI Service Provision at Health Centers of Jimma Town, 2014

\begin{tabular}{|c|c|c|c|c|c|}
\hline Variables & No (\%) & $\begin{array}{l}\text { Unstandardized } \\
\text { Coefficients (B) }\end{array}$ & $\begin{array}{c}\text { Standardized } \\
\text { Coefficients (Beta) }\end{array}$ & Sig. & $\begin{array}{l}95 \% \text { Confidence } \\
\text { Interval for B }\end{array}$ \\
\hline (Constant) & & -0.766 & & 0.092 & $(-1.659,1.127)$ \\
\hline $\begin{array}{l}\text { Sex of caretaker } \\
\text { Male* } \\
\text { Female }\end{array}$ & $\begin{array}{l}216(52.6) \\
195(47.4)\end{array}$ & -0.044 & -0.020 & 0.714 & $(-0.281,0.193)$ \\
\hline $\begin{array}{l}\text { Educational status } \\
\text { Illiterate* } \\
\text { Primary (I-8) } \\
\text { Secondary (9-12) } \\
\text { Above secondary }\end{array}$ & $\begin{array}{l}135(32.9) \\
150(36.5) \\
80(19.4) \\
46(11.2)\end{array}$ & $\begin{array}{l}-0.175 \\
-0.034 \\
-0.207\end{array}$ & $\begin{array}{l}-0.094 \\
-0.015 \\
-0.076\end{array}$ & $\begin{array}{l}0.110 \\
0.785 \\
0.178\end{array}$ & $\begin{array}{l}(-0.389,0.040) \\
(-0.275,0.208) \\
(-0.508,0.095)\end{array}$ \\
\hline $\begin{array}{l}\text { Telling the name of child } \\
\text { illness } \\
\text { Yes } \\
\text { No* }\end{array}$ & $\begin{array}{l}245(59.6) \\
166(40.4)\end{array}$ & 0.223 & 0.123 & $0.017 * *$ & $(0.04 I, 0.406)$ \\
\hline $\begin{array}{l}\text { Receiving first dose of } \\
\text { medications at facility } \\
\text { Yes } \\
\text { No* }\end{array}$ & $\begin{array}{c}53(17.3) \\
254(82.7)\end{array}$ & 0.320 & 0.137 & $0.007^{* *}$ & $0.087,0.552$ \\
\hline $\begin{array}{l}\text { Receiving laboratory services } \\
\text { Yes } \\
\text { No* }\end{array}$ & $\begin{array}{l}105(25.5) \\
306(74.5)\end{array}$ & 0.256 & 0.126 & $0.012^{* *}$ & $(0.455,0.056)$ \\
\hline $\begin{array}{l}\text { Recommending health facility } \\
\text { for relatives } \\
\text { Yes } \\
\text { No* }\end{array}$ & $\begin{array}{c}352(85.6) \\
59(14.4)\end{array}$ & 0.670 & 0.239 & $0.000 * *$ & $(0.387,0.952)$ \\
\hline $\begin{array}{l}\text { Availability of prescribed } \\
\text { medications } \\
\text { - Receiving all medications* } \\
\text {-Receiving some medication } \\
\text { and prescription }\end{array}$ & $\begin{array}{l}265(70.5) \\
111(29.5)\end{array}$ & -0.312 & -0.121 & $0.021 * *$ & $(0.577,0.047)$ \\
\hline
\end{tabular}

Notes: Model Summary $(R=0.649$, $R$ Square $=0$ 0.42I, Adjusted R Square $=0.409)$. *References category (categories with highest frequency taken as reference categories). **Significant at $\mathrm{P}$-value $<0.05$.

studies done in Iran and Uganda where 90\% and $82 \%$ of caretakers had not received advice on how to care their sick children at home, respectively. ${ }^{29,35}$

In our study only $53(17.3 \%)$ children received their first dose of medication at the facility before they left. This finding was lower than the study done in Zimbabwe which was $50 \%{ }^{39}$ and $34 \%$ in KSPA. ${ }^{32}$ However, it was higher when compared to the studies done in Morocco, Iran, and Dhaka, Bangladesh, which indicate that none and/or one of the children received their first dose of medication in the health facility ${ }^{28,34,42}$ and in Tikur Anbessa hospital $(4.8 \%){ }^{41}$ A possible explanation for the difference might be due to the client flow variation at health facilities centers. This might make it difficult to manage all clients properly if the client flow is high due to and also difference in working environment. This needs to be improved as IMNCI recommends that sick children should receive their first treatment in the health facility to avoid unnecessary delay in the initiation of treatment.

In our study it was found that the weighing scale, thermometer, and height or length board were available and functional in all of the 3 health centers while measuring jar of 1 liter, cup- spoon and examination bed were available and functional in one of the health centers. 
Similar findings were reported from the Bhavnagar District, Gujarat. ${ }^{26}$ This study revealed that IMNCI guideline/health workers chart booklet was not available at all health centers. This finding was inconsistent with the study in Bhavnagar district in India (71\%), 10\% in Gujarat of India, ${ }^{26} 82 \%$ in Morocco $^{28}$ and $53 \%$ in Kenya ${ }^{32}$ where the IMNCI chart booklet was available at health facilities. However, a similar with study done in Ahmadabad District, Gujarat. ${ }^{27}$ A possible explanation might be the lack of supportive supervision and follow up that initiates them to adhere to guideline during service provision as it is used as reference for treating children. It might also be due to the difference in refreshment training that was related to child health service.

In the current study, the mean waiting time for the respondents was 44.6 minutes (SD of 3.47). This is lower than the study conducted in Johannesburg of which the mean waiting time of caregivers was 135 (SD of 72) minutes. ${ }^{36}$ This variation might be due to the difference in clients' flow in which only clinics that manage 40 or more patients per day qualified for the study done in Johannesburg. Waiting time resulting from medical and administrative procedures is a critical factor in predicting patient's satisfaction with quality of health care delivery. This means that service delivery with no or little waiting time will positively affect patients' satisfaction.

In our study the most the commonest areas of problems felt by the clients were waiting time (23.4\%), ability to discuss problems or concerns about illness $(32.1 \%)$, and availability of medicines (19.2\%). This finding was consistent with the study conducted in primary health care services in Nnewi, Nigeria where availability of drugs/ vaccines $(37.7 \%)$, cleanliness of facility (35.7\%), amount of explanation received $(34.1 \%) .{ }^{30}$ In our study about $33.6 \%$ of respondents were satisfied on the amount of explanation they received about the problem or treatment of their child's illness. This finding was lower than the study done in Rural Health Units of Assiut Governorate $(79.1 \%)^{40}$ and in Zagazig City, Sharkia of Governorate of Egypt (69.5\%).

This might due to the difference in qualifications of health service providers as most of the service providers in our study were diploma nurses and also might be due to lack of refreshment training. The findings of this study may be affected by some limitations. Health workers being observed may follow the IMNCI guidelines more closely than they would have if they were not observed. It is impossible to estimate the magnitude of this bias (i.e., Hawthorne bias). Social desirability bias might also occur in this study as the respondents were interviewed in the compound of the health facility and there might also introduction of observer bias and there is limitation from our sampling procedure used. This may potentially overestimate the quality of IMNCI service provision.

\section{Conclusion}

Perceived mean of caretakers' satisfaction at the health centers of Jimma town was low as compared to most of earlier studies. And shortage of medicine was still a problem as nearly one fourth of the clients did not receive the prescribed medication from the health centers. Dissatisfaction was more with waiting time, ability to discuss problems or concerns about illness and amount of explanation received about the problem and treatment and satisfaction of caretakers about the drug price was high. Availability of prescribed medication, receiving first dose of medication at health facility and receiving laboratory services were factors found to predict caretaker satisfaction in this study. Respective health centers need to ensure availability of adequate water supply and essential drugs, supplies and re-engineer its operations to decrease dissatisfaction with waiting time by managing time properly like availing of service providers on time to meet the satisfaction of caretakers. Health service providers need to pay special attention on information provision in compliance to the guideline and recommend other studies to measure qualitative aspect of quality measurement.

\section{Abbreviations}

AIDS, Acquired Immune Deficiency Syndrome; ART, Anti retroviral therapy; CI, confidence interval; C-IMCI, Community Integrated Managements of Childhood Illness; DHS, demography and health survey; EDHS, Ethiopian Demographic and Health Survey; EPI, Expanded Program on Immunization; ETB, Ethiopian Birr; GNI, Gross National Income; GSPA, Ghana Service Provision Assessment; HIV, Human Immunodeficiency Virus; HCT- HIV, counseling and testing; IMCI, Integrated Managements of Childhood Illness; IMNCI, Integrated Managements of Newborn and Childhood Illness; KSPA, Kenya Service Provision Assessment; MDGs, Millennium Development Goals; ORS, Oral rehydration salt; PAHO, Pan-American Health Organization; PHCs, primary health cares; PIHCT, provider initiated HIV counseling and testing; SPA, Service Provision Assessment; USPA, Uganda 
service provision assessment; TB, Tuberculosis; WHO, World Health Organization.

\section{Data Sharing Statement}

Data and materials will be available upon request. You can contact Mr. Musa Kumbi, and Mr. Adem Abdulkadir if you want the data and materials at any time.

\section{Ethics Approval and Consent to Participate}

Ethical clearance was obtained from Research Ethics Committee of college of public health and medical sciences of Jimma University in compliance with the Declaration of Helsinki. Moreover, Verbal informed consent was approved by the ethics committee of college of public health and medical sciences of Jimma University. Letter of permission was obtained from Jimma town health department.Finally verbal consent was obtained from the health centres, study participants and service providers included in the study immediately before the data collection. Verbal consent was obtained from guardian (Mother and father) of children under 5. Anonymity and confidentiality was ensured for information obtained from study participants before the Interview and the participants were informed about the purpose of the study.

\section{Authors' Information}

$\mathrm{MK}, \mathrm{AH}$ and AA are Assistant Professor and lecturers at Madda Walabu University respectively.

\section{Acknowledgments}

Authors are thankful to Jimma University Graduate Study program for supporting this study. We are also very thankful to mothers for their collaboration to achieve this study.

\section{Author Contributions}

All authors made substantial contributions to conception and design, acquisition of data, or analysis and interpretation of data; took part in drafting the article or revising it critically for important intellectual content; agreed to submit to the current journal; gave final approval of the version to be published; and agree to be accountable for all aspects of the work.

\section{Funding}

This study was funded by Jimma University, Ethiopia.The University has supported this study financially and technically during the design of the study, collection, analysis, interpretation of data and in writing the manuscript.

\section{Disclosure}

The authors report no conflicts of interest for this work.

\section{References}

1. Tulloch J. Integrated approach to child health in developing countries. Lancet. 1999;354(2):SII16-SII20. doi:10.1016/S01406736(99)90252-0

2. World Health Organization. Integrated management of childhood illness. 2005. Available from: https://apps.who.int/iris/handle/10665/ 42939. Accessed April 1, 2021

3. Bryce J, Victora CG, Habicht J, et al. Programmatic pathways to child survival: results of a multi-country evaluation of Integrated Management of Childhood Illness. Health Policy Plan. 2005;363-8.

4. Rakha MA, Abdelmoneim AM, Farhoud S, et al. Does implementation of the IMCI strategy have an impact on child mortality? Retrospective Analysis Routine Data Egypt. BMJ OPEN. 2013;3 (1);1-10.

5. Mohan P, Kishore B, Singh S, Bahl R, Puri AKR. Assessment of implementation of integrated management of neonatal and childhood illness in India. J Heal Popul Nutr. 2011;29(6):629-638.

6. World Health Organization. Integrated Management of Childhood Illness. 2013.Available from:https://www.who.int/maternal_child_ adolescent/documents/child_hospital_care/en/. Accessed April 1, 2021.

7. El Mahalli AAAO, Akl O. Effect of adopting integrated management of childhood illness guidelines of drug use at a primary health care center: a case study from Egypt. J Fam Commun Med. 2011;18 (3):118-123. doi: 10.4103/2230-8229.90010

8. World Health Organization. Quality of Care/Service Provision Assessment: a process for marketing choices in health system. 2009.Available from:Available from https://www.jfcmonline.com/ text.asp?2011/18/3/118/90010. Accessed March 25, 2021.

9. Fantahun M. G/sillassie T. In what ways can Community Integrated Management of Neonatal and Childhood Illnesses (C-IMNCI) improve child health? Ethiop J Health Dev. 2011;25(2):143-149.

10. World Health Organization. Integrated management of childhood illness: caring for newborns and children in the community. WHO. 2011.

11. World Health Organization. Recommendations for management of common childhood conditions. Evidence for technical update of pocket book recommendations: newborn conditions, dysentery, pneumonia, oxygen use and delivery, common causes of fever, severe acute malnutrition and supportive care. 2012.https://apps.who.int/iris/ handle/10665/44774 . Accessed April 1, 2021.

12. World Health Organization. Redesigning child care: survival, growth and development. 2005. Available from:https://www.who.int/whr/ 2005/chap6-pr.pdf. Accessed March 25, 2021.

13. Al-Qutob R, Mawajdeh S, Laila Nawar SS. Assessing the quality of reproductive health Services. Popul Counc Reg off West Asia North Afri. 2009;13(5).

14. Teutsch C. Patient-doctor communication. US Natl Institutes Health. 2007;87(5):1115-1145.

15. Uzochukwu O. Community satisfaction with the quality of maternal and child health services in Southeast Nigeria. East Afr Med J. 2008;6(81).

16. Shrivastava SRSP. Evaluation of trained Accredited Social Health Activist (ASHA) workers regarding their knowledge, attitude and practices about child health. Rural Remote Health. 2012;12 (4):2099.

17. Pradhan NA, Rizvi N, Sami N, Gul X. Insight into implementation of facility-based integrated management of childhood illness strategy in a rural district of Sindh, Pakistan. Glob Health Action. 2013;6 (1):20086. doi:10.3402/gha.v6i0.20086 
18. Callaghan-Koru JA, Hyder AA, George A, Gilroy KE, Nsona HMAB. Health workers' and managers' perceptions of the integrated community case management program for childhood illness in Malawi: the importance of expanding access to child health services. Am J Trop Med Hyg. 2012;87(5):61-68. doi:10.4269/ ajtmh.2012.11-0665

19. Zhang Y, Van MH, Chen L. Care-seeking and quality of care for outpatient sick children in rural Hebei, China: a cross-sectional study. Croat Med J. 2013;54(6):541-549. doi:10.3325/cmj.2013.54.541

20. Central Statistical Agency. Ethiopia Demographic and Health Survey, Addis Ababa. 2011. Available from:https://dhsprogram.com/pubs/pdf/ fr255/fr255.pdf. Accessed April 1, 2021.

21. Federal Ministry of Health. National strategy for child survival in Ethiopia. 2005. Available from: https://extranet.who.int/nutrition/ gina/sites/default/filesstore/ETH\%202005\%20National\%20Strategy \%20for\%20Child\%20Survival.pdf. Accessed April 1, 2021.

22. Woodward CA. Strategies for Assisting Health Workers to Modify and Improve Skills: Developing quality Health Care: A Process of Change. World Health Organization; 2000.

23. Lohr KN. Medicare:A Strategy for Quality Assurance. Washington DC: J.Qual.Assur.1991;13(1):10-3.

24. Rathod AB, Bhalani KD, Jadav PM, Patel HM, Amin D. Assessment of implementation of integrated management of neonatal and childhood illnesses programme at primary health centre level in Bhavnagar District, Gujarat. Innov J Med Health Sci. 2013;3(6).

25. Apjojb A. Assess the quality of Integrated Management of Neonate \& Childhood illness (IMNCI) services at primary health centre in Ahmadabad district, Gujarat. Indian J Matern Child Health. 2010;12 (4):1-8.

26. World Health Organization. Quality of Outpatient Primary Child Health Care Services in Morocco. WHO; 2007. Available from https://apps.who.int/iris/handle/10665/116576. Accessed April 1, 2021.

27. USAID. Uganda Service Provision Assessment Survey. Assessment Survey Policy Brief: Child Health. 2007. Available fromhttps:// dhsprogram.com/pubs/pdf/PB3/PB3.pdf. Accessed April 1, 2021.

28. Pou A, Ckc N, Ue E. Caregivers 'satisfaction and supervision of primary health care services in Nnewi, Nigeria. Niger J Paediatr. 2012;39(4):179-184.

29. Nkosi ZZ, Botshabelo RL, Jorosi H, Makole NS, Nkomo G, Ruele SL. The implementation of the integrated management of childhood illnesses (IMCI) strategy guidelines in Botswana. Afr J Nurs Midwifery. 2012;14(2):90-103.

30. USAID.Kenya Service Provision Assessment Survey.; Kenya; Survey; ICF Macro. 2011. Available from: https://dhsprogram.com/ pubs/pdf/SPA17/SPA17.pdf. Accessed April 1, 2021.

31. Modes PS, Gaiva MA. Users 'satisfaction concerning the care delivered to children at primary healthcare services. Escola Anna Nery. 2013;17(3):455-465.

32. Hasan A, Chompikul J, Bhuiyan SU. Patient satisfaction with maternal and child health services among mothers attending the Maternal and Child Health Training Institute in Dhaka. J Public Health Dev.2007;5(3):23-33.

33. Roodpeyma S. Integrated Management of Childhood Illness in Outpatient Department of a University Hospital. Iranian Journal Of Pediatric Society.2010;2(1):20-25.

34. Thandrayen K, Bch MB, Sa F, Paed M. Quality of care offered to children attending primary health care clinics in Johannesburg. South Afr J Child Health. 2010;4(3):73-77.
35. Oladele EA, Ormond L, Adeyemi O, et al. Tracking the quality of care for sick children using lot quality assurance sampling: targeting improvements of health services in Jigawa, Nigeria. PLoS One. 2012;7(9).

36. Horwood C, Vermaak K, Rollins N, Haskins L, Nkosi P, Qazi S. An evaluation of the quality of IMCI assessments among IMCI trained health workers in South Africa. PLoS One. 2009;4(6):2-7.

37. Habimana P Assessment of the quality of IMCI implementation in four districts in Zimbabwe. 2010. Available from:http://wiredspace. wits.ac.za/handle/10539/7674. Accessed March 25, 2021. Accessed April 1, 2021.

38. Ahmed SM. Assessment of health services provided for children by rural health units of Assiut governorate. J Am Sci. 2013;9(2):32-45.

39. Endrias T. Assessment maternal and child health service provision in Tikur Anbessa General Specialized Hospital [on the internet]; 2005. Available from: http://etd.aau.edu.et/bitstream/handle/123456789/ $8465 /$ Tesfaye $\% 20$ endrias.pdf?sequence $=1 \&$ isAllowed $=y$. Accessed April 1, 2021.

40. Aniza I, Rizala MM, Ng YS, et al. Caregivers' satisfaction of healthcare delivery at paediatric clinics of Universiti Kebangsaan Malaysia Medical Centre. Med J Malaysia. 2011;66(2):84-88.

41. Pal R, Das P, Basu M, Tikadar T, Biswas GC, Mridha P. Client satisfaction on maternal and child health services in rural Bengal. Indian $J$ Commun $\quad$ Med. 2010;35(4):478. doi:10.4103/09700218.74344

42. Abd Allah E, Elsabagh E, El Awady S. Mother's satisfaction with the quality care of maternal \& child health services at maternal and Child Health Centers in Zagazig City, Sharkia Governorate, Egypt. Life Sci J. 2012;9(3):1438-1448.

43. National Coordinating Agency for Population and Development (NCAPD) [Kenya], Ministry of Medical Services (MOMS) [Kenya], Ministry of Public Health and Sanitation (MOPHS) [Kenya], Kenya National Bureau of Statistics (KNBS) [Kenya], ICF Macro. 2011. Kenya Service Provision Assessment Survey. 2010. Available fromhttps://dhsprogram.com/pubs/pdf/SPA17/SPA17.pdf. Accessed April 1, 2021.

44. Federal Democratic Republic of Ethiopia Ministry of Health. Integrated management of newborn and childhood illness. Chart booklet for health. 2012. Available fromhttps://www.open.edu/open learncreate/pluginfile.php/71990/mod_resource/content/2/IMNCI_ Part_1_Final_Print-ready_March_2011_.pdf. Accessed April 1, 2021.

45. Fongwa MN, Hays RD, Gutierrez PR, Stewart AL. Patient satisfaction instrument tailored to the concerns of African Americans. Ethn Dis. 2006;16(4):948.

46. Patel H, Nayak A, Bhalani K, Kotecha I, Singh MP. Rapid assessment of IMNCI programme in Bhavnagar District, Gujarat. Natl J Integr Res Med. 2013;4(6):20-26.

47. Atinga RA, Abekah-Nkrumah G, Domfeh KA. Managing healthcare quality in Ghana: a necessity of patient satisfaction. Int $J$ Healthc Qual Assur. 2011;24(7):548-563. doi:10.1108/09526861111160580

48. El Arifeen S, Blum LS, Hoque DM, et al. Integrated Management of Childhood Illness (IMCI) in Bangladesh: early findings from a cluster-randomised study. Lancet. 2004;364:1595-1602. doi:10.1016/S0140-6736(04)17312-1 


\section{Publish your work in this journal}

Patient Preference and Adherence is an international, peer-reviewed, open access journal that focusing on the growing importance of patient preference and adherence throughout the therapeutic continuum. Patient satisfaction, acceptability, quality of life, compliance, persistence and their role in developing new therapeutic modalities and compounds to optimize clinical outcomes for existing disease

states are major areas of interest for the journal. This journal has been accepted for indexing on PubMed Central. The manuscript management system is completely online and includes a very quick and fair peer-review system, which is all easy to use. Visit http:// www.dovepress.com/testimonials.php to read real quotes from published authors.

Submit your manuscript here: https://www.dovepress.com/patient-preference-and-adherence-journal 